Article

\title{
Service Organisations' Cultural Competency When Working with Ethnic Minority Victims/Survivors of Child Sexual Abuse: Results from a Program Evaluation Study in Australia
}

\author{
Pooja Sawrikar ${ }^{D}$ \\ School of Human Services and Social Work, Griffith University, Gold Coast 4222, Australia; \\ p.sawrikar@griffith.edu.au
}

Received: 29 July 2020; Accepted: 28 August 2020; Published: 3 September 2020

check for updates

\begin{abstract}
Founded in the results of a systematic literature review, a professional development program was developed about the needs of ethnic minority victims/survivors of child sexual abuse, with one component on the role of organisations. The objective was to address the misperception that frontline workers are more responsible for cultural competency. The program was delivered across Australia in $2019(\mathrm{~T} 1 \mathrm{n}=112, \mathrm{~T} 2 \mathrm{n}=44)$. Data collection for the program evaluation was conducted over six months using a mixed-methods design. The results show that: (a) a sizeable portion of organisations $(16 \%)$ do not have any ethnic minority staff, and very few are in management positions $(6-13 \%)$; (b) ethnic minority staff, and staff in organisations specialised for ethnic minority communities, offer choice to clients about ethnically-matched service providers more often; (c) there is evidence supporting the usefulness of ongoing training; (d) the use of a multicultural framework was rated higher 'in principle' than 'in practice', and ratings increased after the program; (e) the proportion of organisations collecting ethnicity-related data did not increase over time; (f) all organisations specialised for ethnic minority communities had visually inclusive websites but was only $54 \%$ for mainstream organisations; and (g) organisations specialised for ethnic minority communities have stronger links with other local ethnic minority community organisations. Overall, the program is seen as useful for promoting cultural competency at the organisational level; clearly identifying key mandatory and ideal elements, which support good practice with this highly vulnerable and marginalised client group.
\end{abstract}

Keywords: child sexual abuse; ethnic minorities; cultural competency; white privilege; intersectionality; multicultural framework

\section{Introduction}

\subsection{Background and Hypotheses}

It is well established in the literature (e.g., Futa et al. 2001; Sawrikar 2017; Tishelman and Geffner 2010) that little is known about the needs and experiences of ethnic minority victims/survivors of child sexual abuse (CSA). The neglect largely reflects that culture, race, and migration are seen as marginal issues. Multiculturalism in Australia, and other comparable western countries, such as the United States, United Kingdom, Canada, and New Zealand, force researchers to challenge any universalist assumptions they may otherwise make about the psychosocial experience of CSA. However, that level of critical reflection and self-awareness requires a need and want to engage with the cognitive and emotive load of how to work with ethnic minority communities ethically and with children safely in ways that do not make these two goals compete. It is therefore not surprising that these factors are only slowly beginning to be addressed in the national and international literature base. 
Political sensitivities and 'hierarchies of evidence' also make publishing and funding in this area difficult (Sawrikar 2019a, 2018a; Sawrikar and McAuliffe 2019), leaving practitioners to learn about this client group on-the-go and from the few who break through all the barriers to help-seeking (Sawrikar and Katz 2017a) without a broader theoretical framework to help contextualise and instil confidence in their acquired practice wisdom.

Ethnic minorities are also a 'hard to reach' group in terms of conducting research and meeting their clinical service needs because of cultural and racial pressure to remain silent; that is, to protect their family name (Chan et al. 2011; Gilligan and Akhtar 2005; Lesmana et al. 2015; Ma and Li 2014; Sulimani-Aidan and Benbenishty 2013; Ullman and Filipas 2005) and their whole community from racist stereotyping (Bernard 2002; Fontes and Plummer 2010; George et al. 2014; Shalhoub-Kevorkian 2000; Wilson 1994). Overt value for traditional gender roles in highly patriarchal societies intensifies sexism as an additional silencing factor (Alaggia 2001; Allimant and Ostapiej-Piatkowski 2011; Boakye 2009; Fattah and Kabir 2013; Haboush and Alyan 2013; Jewkes et al. 2005; Kanukollu and Mahalingam 2011; Karthiga et al. 2014; Meng 2002; Plummer and Njuguna 2009; Reavey et al. 2006; Sawrikar 2018b; Stewart 2005). As such, it is not easy to conduct extensive literature reviews on sub-themes, such as the one addressed in this paper on the cultural competency of organisations who work with this client group. Instead, it calls for the development of theoretical rationales; that is, ideas with cogency for consideration. Indeed, a recent systematic literature review conducted in 2016 in the broad area of CSA and ethnic minority communities (albeit with stringent inclusion/exclusion criteria to ensure relevancy to the Australian context) only located 135 peer-reviewed articles published between 2000 and 2016 across the developing and developed world (the results of which are published here: Sawrikar and Katz 2018a; Sawrikar and Katz 2018b; Sawrikar and Katz 2017a; Sawrikar and Katz 2017b; Sawrikar and Katz 2017c). Compared to approximately 15,000 research papers based on western (mostly white) samples published in that same period (Sawrikar 2019b), this cannot be regarded as a sufficient body of work.

A more extensive definition of 'ethnic minorities' can be found elsewhere (Sawrikar 2017). Briefly, they refer to first-, second-, or later-generation members of migrant and refugee communities living in western countries, including those of mixed phenotypic race, and so are distinguished from First Nation people and the Anglo mainstream. They tend to originate from non-English speaking countries, and may not be of Christian faith dominant in the west. They also tend to come from countries high on collectivism or 'familism' (Hofstede 1980), and therefore value social roles and responsibilities that prioritise family over individual goals, such as protecting family honour and cohesion, community standing, filial piety, and hierarchical distributions of power to males and older people (Bond 2002; Triandis 1990). Finally, they tend to be visibly different, such as in skin colour or religious/cultural attire (Sawrikar 2017). Thus, non-Indigenous ethnic minorities differ from white-majority westerners in any of the four main dimensions of 'ethnicity' defined by O'Hagan (1999)—language, religion, culture, and race. More accurately, they can be described as ethnic minoritised communities (Di Angelo 2018) to highlight that it is not population size that determines minority-majority status but globalised white power and privilege. However, this term has not been used in this paper only for language ease. In Australian social policy, this group are referred to as the 'Culturally and Linguistically Diverse' (CALD). This term was used on the evaluation instrument in this study for consistency with national protocol but is not ideal (see Sawrikar and Katz 2009 for an in-depth critique).

To help gently prise open the lid on the current paucity of (especially national) research and knowledge in the field, and stimulate ethical dialogue of this highly sensitive and complex issue, a three-staged project was designed; in turn, informed by the results of the systematic literature review conducted in 2016. Stage 1 engaged with service providers in 2019 by developing, delivering, and evaluating a professional development education/training program that aimed to improve their and their organisation's cultural competency (note: this program has since been converted to online mode to be accessible internationally; www.nomoresilence.info). Stages 2 and 3 will be conducted pending funding. Stage 2 will engage with ethnic minority communities to increase their awareness of 
CSA, and Stage 3 will work with culturally diverse schools to deliver and evaluate prevention programs that are culturally informed and sensitive. All three target audiences require understanding of the fundamental necessity to be committed to responsible uses of white and male privilege.

There were eight research questions in Stage 1 of this study. They map to the full content of the program (see Table 1). For brevity, the results of only one research question are being reported on here, with the remaining reported elsewhere (in preparation). Specifically, this paper reports on the findings to the question: Six months post program attendance, do service organisations more appreciate the need for organisational support to provide good practice to ethnic minority victims/survivors of CSA? A number of organisational elements were examined. Those relating to working with interpreters are reported in another paper due to being a substantive practice issue. The remaining nine relevant hypotheses derived from the overarching research question and reported on in this paper are listed in Table 4.

\subsection{Theoretical Rationale}

\subsubsection{Cultural Competency at the Organisational/Institutional Level}

As described more fully elsewhere, there are three main levels to cultural competency within the social services sector: personal, organisational, and institutional (Sawrikar and Katz 2008). The latter two may be merged if the organisation is small. The implication is that good service provision does not all belong to the frontline service provider, who is often and falsely seen as most or more important for delivering cultural competency than the local organisation in which they work on a daily basis or the larger institution to which they belong. For example, Chand and Thoburn (2005) say, "the relationship between family members and the worker, and the personal and professional qualities of the workers, make the major contribution to personal satisfaction for ethnic minority families in the child protection system" (p. 176). However, Chuan and Flynn (2006) argue that the effective development of cultural competency lies beyond the efforts of social workers and agencies, and policies and changes to practice are also necessary for an improved culturally competent environment. Thus, all three tiers are seen to be equally responsible because the likelihood of good outcomes among clients is increased when service providers are supported structurally by their service organisation and institution (Sawrikar 2017).

\subsubsection{Mandatory Elements}

In this project, several elements of organisational/institutional support were seen as essential for delivering services high in cultural competency for ethnic minority victims/survivors of CSA. These elements were derived from the results of the systematic literature review conducted by the author in 2016 on cultural competency in relation to victims/survivors of CSA, and a three-year postdoctoral study conducted by the author between 2007 and 2010 on cultural competency in the child protection system more broadly. That is, they are informed by long-standing research in the sector. They are therefore also consistent with the work of other seminal researchers in the field. More extensive information on these elements can be found in a book dedicated to the issue of cultural competency in child protection service delivery (Sawrikar 2017). Summarily, essential elements include:

1. Using interpreters trained in matters to do with sexual assault, and service organisations providing such training to interpreters, to minimise risk of escalated harm from the use of untrained interpreters (Hall and Valdiviezo 2020; Maiter et al. 2017; Sawrikar 2015; Westlake and Jones 2018).

2. Having an ethnically diverse workforce, including in management positions, to offer choice to clients about ethnically-matched service providers and increase decision-making power to implement policies that promote the decolonisation of knowledge and practice within social work and related disciplines (Ahmed 2004; Giglio 1997; Hackett and Cahn 2004; Maitra 2005; Westby 2007).

3. Providing regular 'cultural competency' training, to address staff turnover and respond to new and emerging communities (Barn et al. 1997; Osterling et al. 2005; Welbourne 2002). 
4. Using 'a multicultural framework', and thus fundamentally valuing cultural differences (Babacan 2006; Boushel 2000; Chand and Thoburn 2005; Gough and Lynch 2002; Harran 2002; Korbin 2008; Yick 2007).

5. Collecting data on all ethnicity-related variables, to precisely monitor who is and is not accessing their services from the local community (Chuan and Flynn 2006; Thanki 2007).

\subsubsection{Ideal Elements}

In this project, two elements of organisational cultural competency were ultimately categorised as ideal rather than essential. The first was that organisations use visual images of a target client group that is ethnically diverse in their promotional materials, such as website, pamphlets, etc., consistent with the call of other scholars (Allimant and Ostapiej-Piatkowski 2011; Fontes 2005; Weeks 2002). This element was not identified as essential to help recognise the severe lack of resources common within the social services sector. However, it could also be counter-argued that even within finite and pressured funding constraints, decisions that reflect investment in ethnic diversity do not implicitly condone 'white privilege' as if poor resourcing is an acceptable justification. Overall, larger organisations with greater financial power are seen to be more responsible for delivering on this element than smaller organisations who may not have the financial capacity to rebrand their website and other promotional materials if required.

The second element identified as ideal for cultural competency was having strong links with local ethnic minority community members and organisations, which several other researchers also note as important (Chuan and Flynn 2006; Chand 2005; Osterling et al. 2005; Sale 2006; Walker 2002). This element was not seen as essential to help acknowledge in advance that not all communities across Australia have high ethnic minority densities, and therefore links with such organisations would/should reflect the local milieu and respond accordingly.

\section{Method}

\subsection{Program Development}

The core content of the Stage 1 program was informed by the results of the systematic literature review conducted in 2016. It reflects three overlapping bodies of knowledge about (i) CSA, (ii) ethnic minority communities, and (iii) good service provision, as conceptually shown in Figure 1.

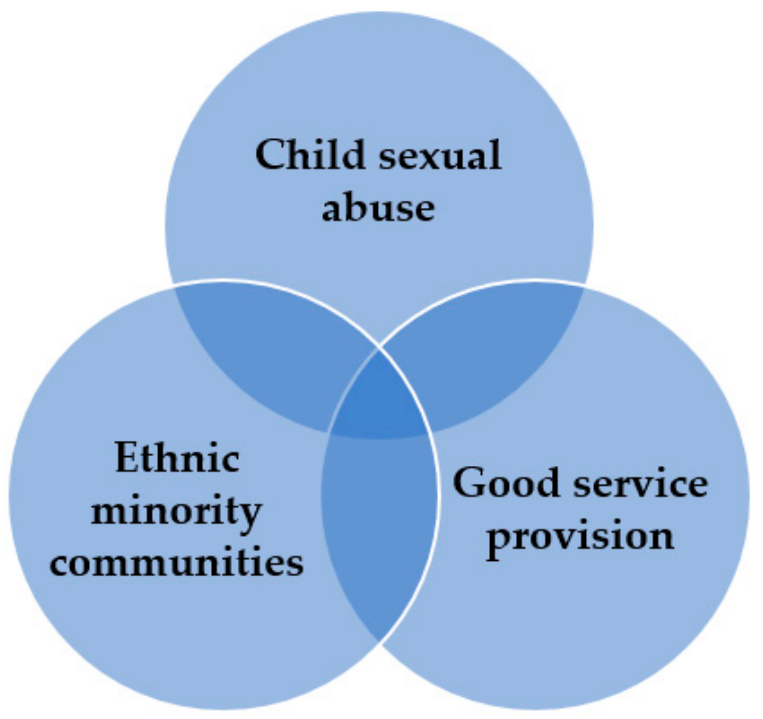

Figure 1. Three overlapping 'circles' of knowledge required for good service provision for ethnic minority client victims/survivors of CSA. 
Members of the target audiences (see Section 2.3 for more information) may have good knowledge about one or two of these elements but not necessarily the others, and therefore how they merge together would constitute as unique learning for them and investment in future capacity building within their organisation. Alternatively, this issue may be their core business with the program; instead, offering affirmation of their knowledge and opportunity to reflect on current practice and research findings. As stated previously, Table 1 summarises the full scope of the program content, but only the results relating to the elements under 'organisational/institutional factors' (except regarding interpreters) are reported here (italicised).

Table 1. Full program scope/coverage.

\begin{tabular}{|c|c|}
\hline \multicolumn{2}{|r|}{ Knowledge about CSA and Ethnic Minority Communities } \\
\hline & $\begin{array}{l}\text { - Prevalence is high across all cultures } \\
\text { - Likely perpetrators are those known to the victim, rather than unknown strangers } \\
\text { - Myths about CSA reflect false beliefs that can shift culpability to the victim } \\
\text { - Supportive responses to disclosure are critical for mediating mental ill-health } \\
\text { - Family reputation is of utmost importance in ethnic minority communities high } \\
\text { on collectivism } \\
\text { - Relying on extended family and community for child rearing and child safety is } \\
\text { normative in collectivist cultures } \\
\text { - Discussing any matters to do with sex, including abuse, is a social taboo } \\
\text { - Racism is a unique barrier to disclosure of CSA among ethnic minority communities }\end{array}$ \\
\hline \multicolumn{2}{|r|}{ Knowledge about service provision for ethnic minority victims/survivors of CSA } \\
\hline Personal factors & $\begin{array}{l}\text { - Having a sense of efficacy (including cultural knowledge, confidence, and } \\
\text { sensitivity/respect) in working with ethnic minority client victims/survivors of CSA } \\
\text { - Being aware of and sensitive to non-ethnic factors for ethnic minority client } \\
\text { victims/survivors of CSA } \\
\text { - Being aware of the pros and cons of medicalising mental illness due to CSA over the } \\
\text { use of a sociological framework in ethnic minority communities } \\
\text { - Being aware of and constructively engaging with the concept of 'white privilege' } \\
\text { - Encouraging additional self-help, family, and group therapy to avoid professional } \\
\text { omnipotence in a one-on-one setting }\end{array}$ \\
\hline $\begin{array}{c}\text { Organisational/ } \\
\text { institutional factors }\end{array}$ & $\begin{array}{l}\text { - Having an ethnically diverse workforce, including in management positions } \\
\text { - Using interpreters trained in matters to do with sexual assault and providing } \\
\text { such training } \\
\text { - Providing regular training in cultural competency to staff to respond to new and emerging } \\
\text { communities and staff turnover } \\
\text { - Using 'a multicultural framework' within the service organisation's mission statements, } \\
\text { philosophies, practice frameworks, etc. } \\
\text { - Mandatorily collecting data on ethnicity-related variables (e.g., country of birth, languages } \\
\text { spoken at home, etc.) }\end{array}$ \\
\hline
\end{tabular}

\subsection{Ethics and Endorsement}

Ethics approval for all materials used in Stage 1, including the evaluation instrument designed to collect data on the eight research questions, was obtained from Griffith University's Human Research Ethics Committee (GU HREC Approval No. 2018/953). The project observes ethical principles identified in the 2018 Ethical Research Code of Conduct, including informed consent, voluntary participation, arms-length recruitment, permission to record, deidentified research outputs, and language that is non-racist, non-sexist, and non-defamatory of victims/survivors of CSA, ethnic minority, Indigenous, and Anglo communities. Continuing Professional Development (CPD) endorsement was also obtained for the program from the Australian Association of Social Workers (Reference No. AASW181112).

\subsection{Recruitment and Delivery}

Organisations that provide direct support to victims/survivors of CSA in the form of mental health services and advocacy, and therefore including counsellors, social workers, psychologists, general practitioners (GPs), and psychiatrists, formed a primary target audience for the program. 
Organisations that do not provide direct support services but rather conduct research or provide information or professional training about sexual assault, other forms of violence (e.g., domestic and family violence (DFV), intimate partner violence (IPV), gender-based violence (GBV), etc.), or all forms of child maltreatment (i.e., physical abuse, sexual abuse, emotional abuse, and chronic neglect) formed another primary target audience group.

In total, 267 organisations in four culturally diverse cities in Australia-Sydney, Melbourne, Brisbane, and Adelaide-were invited via email in January 2019 to attend the program. The programs were then delivered in each city within one week during March-April 2019, in the neutral space of hotel meeting rooms that also provided catering and IT (Information Technology) support.

The program was delivered as a half-day training course, for which registrants received five CPD hours. It first involved an introduction that included establishing boundaries on the need for psychological and cultural safety and respect when sharing. Next, the Ethics Information Statement was worked through together as a group to ensure clarity of ethical rights before providing written informed consent to take part in the evaluation study. These included that participation was voluntary, and that all research outputs would be deidentified. The baseline survey was then administered and completed individually by participants. Following this, the program content as stated in Section 2.1 was delivered, with a break for morning tea. Lunch was informally served at the end with the open Q\&A forum, in which participants could ask further questions or make comments from their own professional experiences. Permission to record the forum for accurate transcription was also obtained. It was explained their contributions would be used to finalise the content of the program before it was converted to online mode to be internationally accessible for CPD training purposes. Finally, the anonymous program satisfaction survey was administered.

It is preferable for program evaluations to be independent from the program deliverer to improve trust in the data obtained; social desirability could compromise validity. Thus, the issue of possible perceived conflict of interest was addressed as best as possible by: iterating often that all survey material was completely anonymous; explicitly explaining the importance of researcher independence from the collation of data; collecting baseline data before the program was delivered and rapport was established; and asking registrants to place themselves the anonymous baseline and program satisfaction surveys in a box marked 'confidential' at the back of the room.

\subsection{Baseline and Follow-Up Sample Description}

Table 2 summarises frequency data about the sample collected from the baseline (in person) and six-month follow-up (online) surveys. At T1, there were 112 attendees that completed the baseline (BL) survey, and 44 completed the follow-up (FU) survey at T2 (retention rate $40 \%$ ). At both waves, there were substantially more females, most were social workers, and there were a roughly even number of service providers from an ethnic minority or Anglo background. At T1, attendees varied in age from 23 to 70 years $(M=42.4, S D=12.0, n=112)$, and at $T 2$ from 25 to 70 years $(M=44.5, S D=12.6, n=42)$. At $\mathrm{T} 1$, attendees varied in relevant work experience from 0.5 to 49.5 years $(\mathrm{M}=14.1, \mathrm{SD}=11.1, \mathrm{n}=111)$, and at $\mathrm{T} 2$ from 2 to 38 years $(\mathrm{M}=15.1, \mathrm{SD}=10.4, \mathrm{n}=42)$. In total, 53 organisations were represented in the study at T1 and 33 at T2. Most were service organisations, some were specialised for ethnic minority communities (i.e., multicultural or ethno-specific), and a sizeable proportion were specialised for sexual assault and/or DFV. The remainder were mainstream organisations not focused on specific groups or issues (note: in this paper, the following terms are used synonymously-multicultural organisations, non-mainstream organisations, and CALD-specialised organisations). 
Table 2. Frequency sample data.

\begin{tabular}{ccccc}
\hline & \multicolumn{2}{c}{ T1 } & \multicolumn{2}{c}{ T2 } \\
\cline { 2 - 5 } Total & $\mathbf{N}$ & $\%$ & $\mathbf{N}$ & $\%$ \\
\hline Gender & 112 & 100 & 44 & 100 \\
Female & & & & \\
Male & 101 & 90.2 & 39 & 88.6 \\
No answer & 11 & 9.8 & 4 & 9.1 \\
\hline Cultural background & 0 & 0.0 & 1 & 2.3 \\
\hline Ethnic minority (including mixed race and all generations) & 59 & 52.7 & 23 & 52.3 \\
Anglo (including all generations) & 53 & 47.3 & 21 & 47.7 \\
\hline Service provider type & & & & \\
Social worker & 56 & 50.0 & 23 & 52.3 \\
Counsellor & 16 & 14.3 & 4 & 9.1 \\
Psychologist & 12 & 10.7 & 5 & 11.4 \\
Other (including researcher) & 28 & 25.0 & 10 & 22.7 \\
No answer & 0 & 0.0 & 2 & 4.5 \\
\hline Organisation type & & & & \\
Service organisation & 47 & 90.4 & 29 & 87.9 \\
University & 3 & 5.8 & 0 & 0.0 \\
Private practice & 3 & 3.8 & 1 & 3.0 \\
No answer & 0 & 0.0 & 3 & 9.1 \\
\hline Specialised for ethnic minority groups & 13 & 26.0 & 7 & 21.2 \\
Specialised for sexual assault (including DFV) & 19 & 38.0 & 6 & 18.2 \\
\hline
\end{tabular}

\subsection{Measures and Analysis}

Program attendees were asked several questions that measured cultural competency at the organisational/institutional level. See the technical report (Sawrikar 2019b) for the full evaluation instrument. The relevant questions are summarised in Table 3. 
Table 3. Relevant variables assessing organisational cultural competency, question wording, and response options from the full program evaluation instrument.

\begin{tabular}{|c|c|c|}
\hline Variable & Question & Response Options \\
\hline \multirow{3}{*}{$\begin{array}{l}\text { Ethnic minority } \\
\text { staff } \\
\text { representation }\end{array}$} & $\begin{array}{l}\text { Does your organisation have service provider staff from CALD backgrounds (including those } \\
\text { of mixed ethnicity)? }\end{array}$ & $\begin{array}{l}\text { Mutually exclusive options: } \\
\text { - Yes } \\
\text { - No } \\
\text { - N/A (I do not work at a service organisation) }\end{array}$ \\
\hline & $\begin{array}{l}\text { If yes: } \\
\text { (a) how many in total? } \\
\text { (b) how many of these are in management positions? } \\
\text { (c) what is the total service provider staff size of your local office? __ ; and } \\
\text { do not include administrative staff). }\end{array}$ & \\
\hline & $\begin{array}{l}\text { If yes, does your service organisation offer CALD client victims/survivors of child sexual } \\
\text { abuse choice about whether they would like an ethnically-matched service provider? }\end{array}$ & $\begin{array}{l}\text { Mutually exclusive options: } \\
\text { - Yes } \\
\text { - No } \\
\text { - N/A (We have no CALD clients) }\end{array}$ \\
\hline $\begin{array}{l}\text { Cultural } \\
\text { competency } \\
\text { training }\end{array}$ & $\begin{array}{l}\text { Have you ever received training on culturally appropriate service provision for CALD client } \\
\text { victims/survivors of child sexual abuse while working at your organisation? }\end{array}$ & $\begin{array}{l}\text { Mutually exclusive options: } \\
\text { - Yes (If yes, by whom? e.g., another staff member, a local community } \\
\text { organisation, etc.? } \\
\text { - No } \\
\text { - N/A (I do not work at a service organisation) }\end{array}$ \\
\hline \multirow{2}{*}{$\begin{array}{l}\text { Use of } \\
\text { 'multicultural } \\
\text { framework' }\end{array}$} & $\begin{array}{l}\text { How respectful of ethnic diversity (i.e., race, culture, language, and/or religion) do you feel } \\
\text { your organisation is in principle (e.g., in mission statements, philosophy, practice } \\
\text { frameworks, etc.)? }\end{array}$ & Likert scale options varying from $1=$ Not at all to $5=$ Completely \\
\hline & $\begin{array}{l}\text { How respectful of ethnic diversity (i.e., race, culture, language, and/or religion) do you feel } \\
\text { your organisation is in practice (i.e., daily work)? }\end{array}$ & Likert scale options varying from $1=$ Not at all to $5=$ Completely \\
\hline
\end{tabular}


Table 3. Cont.

\begin{tabular}{|c|c|c|}
\hline Variable & Question & Response Options \\
\hline \multirow[b]{2}{*}{ Data collection } & Does your organisation collect data on ethnicity-related variables for its CALD clients? & $\begin{array}{l}\text { Mutually exclusive options: } \\
\text { - Yes } \\
\text { - No } \\
\text { - N/A (We have no CALD clients) } \\
\text { - N/A (I do not work at a service organisation) }\end{array}$ \\
\hline & If yes, which ones? (Please tick all that are relevant) & $\begin{array}{l}\text { Options: } \\
\text { (a) Languages spoken at home } \\
\text { (b) Need for interpreter } \\
\text { (c) Country of birth } \\
\text { (d) Citizenship (e.g., Australian, permanent resident, temporary resident, refugee, } \\
\text { asylum seeker, etc.) } \\
\text { (e) Religion } \\
\text { (f) Other }\end{array}$ \\
\hline $\begin{array}{l}\text { Links with local } \\
\text { ethnic minority } \\
\text { organisations }\end{array}$ & $\begin{array}{l}\text { How strong would you rate the links of your organisation with other local CALD community } \\
\text { organisations and/or members within them? }\end{array}$ & $\begin{array}{l}\text { Likert scale options: } \\
1=\text { Not at all strong (we have no links with local CALD community organisations } \\
\text { or members of such organisations) } \\
2=\text { Somewhat strong (we have had some contact with local CALD community } \\
\text { organisations or members within them but it is not regular) } \\
3=\text { Quite strong (we have regular contact with local CALD community } \\
\text { organisations or members within them) } \\
4=\text { Very strong (our links with local CALD community organisations or members } \\
\text { within them could be described as excellent) }\end{array}$ \\
\hline
\end{tabular}


The homepage of the websites of all 57 organisations that attended the program were also explored for their visual inclusiveness, just prior to the program being delivered in that city and then again six months later. Thus, data on this element of organisational/institutional cultural competency was not collected from attendees. This helped ensure accurate data was collected, and was not subject to potentially poor recall.

Importantly, change over time was not statistically tested in this study; it was only described, with speculation about the possible effectiveness of the program in contributing to observed changes. This is because the longitudinal study design intentionally selected 'cohort' rather than 'panel'. A panel study generally requires a large sample that links the data sets over time with a unique identifier. To allow data collection to be and be perceived as completely anonymous, no such identifier was used; this was critical due to how sensitive the topic is. Thus, obtaining valid data at each time point (T1 and T2) was seen as more important than having a matched sample over time that would permit repeated measures statistical analyses, especially on such a small cross-wave sample.

Qualitative data was obtained from feedback in response to open-ended questions on the anonymous program satisfaction survey, as well as from the open Q\&A forums. These forums were relatively lengthy, ranging from 30 to $60 \mathrm{~min}$, and thus providing substantive qualitative data to help triangulate findings from the quantitative survey. The stance of the forums was to decentralise the researcher as the expert in the field, and ensure and encourage the mutual and respectful full sharing of knowledge and experiences with informed and curious practitioners. Nearly all relevant verbatim quotes have been presented, to showcase the range of discussion, provide indirect information about the number of participants engaging with each discussion point, and to fully represent the voices, knowledge, and experience of the participants (Denzin and Lincoln 2018).

Typically, a small number of exemplar quotes are selected for description and analysis of key themes and sub-themes. However, as this topic is highly sensitive in Australia, sharing thoughts, ideas, and experiences depend on a high degree of trust and vulnerability within the group, who also came from a range of practice and organisational backgrounds and therefore did not all know each other. Honouring and representing the full array of their voices by listing all relevant quotes is a way of thanking participants for their important contributions. That is, it demonstrates the implementation of utmost commitment to researcher privilege, rather than briefly summarising their voices away.

\section{Results}

As there were many variables under investigation, the results are presented in summary format first in Table 4. Further details surrounding the overall result follow in the sections thereafter.

Table 4. Summary of the overall results for all nine hypotheses.

\begin{tabular}{lc}
\hline HYPOTHESES-Six Months after Attending the Education Program: & SUPPORTED \\
\hline 1. The proportion of service provider staff from an ethnic minority background employed by a service & $\times$ \\
organisation will increase. & $\times$ \\
2. The proportion of service provider staff from an ethnic minority background employed in a management \\
position by a service organisation will increase. & $\times$ \\
3. The frequency of choice offered to ethnic minority client victims/survivors of CSA about having or not \\
having an ethnically-matched service provider will increase. \\
4. The number of service organisations that provide training on culturally appropriate service provision for \\
ethnic minority client victims/survivors of CSA will increase. \\
5. Service providers will increase their rating of their service organisation's value for a 'multicultural \\
framework' within mission statements, philosophies, practice frameworks, etc. \\
6. Service providers will increase their rating of their service organisation's implementation of a \\
'multicultural framework' within daily practice work. \\
7. The number of service organisations that collect data on ethnicity-related variables will increase. \\
8. The number of service organisations with visually inclusive websites will increase. \\
9. Service providers will increase their rating of their service organisation's links with local ethnic minority \\
community organisations. & $\checkmark$ \\
\hline
\end{tabular}




\subsection{Ethnic Minority Staff and Choice Regarding Matching}

\subsubsection{Representation of Ethnic Minority Staff}

At T1, participants within an organisation provided the same responses to each other to the first part of the relevant question, so the unit of analysis could remain the organisation in line with the hypotheses (rather than adjusting it to the service provider). Participants from five organisations selected ' $\mathrm{N} / \mathrm{A}^{\prime}$ because they worked at a university, were a student on field placement, or did not work in frontline services, and one participant did not answer this question because they were in private practice. Of the remaining 45 organisations, 38 (84\%) said that CALD staff were employed there. However, this leaves $16 \%$ of organisations that do not have any ethnic minority representation.

At T2, two participants from one organisation provided different responses to each other. However, of the remaining 26 service organisations represented in the follow-up data set, 25 (96\%) said that CALD staff were employed there, and one private practitioner was self-identified as being of CALD background. This suggests that service organisations with diversity in their staff profile were most interested in the program than those without, and keen to be involved in the study over a longer term.

The second part of this question was designed to explore what proportion of staff are ethnic minority and how many are in management positions, however the data that was collected needs to be treated with caution: (i) 34 participants at T1 and 16 at T2 did not answer a, b, or c; (ii) 19 at T1 said they were 'Not sure' about a, b, or c; (iii) six at T1 and six at T2 did not provide logically consistent answers, with number of CALD staff either exceeding total staff size or equalling it but additionally identifying CALD staff in management positions; (iv) at both $\mathrm{T} 1$ and $\mathrm{T} 2$, responses from participants within organisations varied from one another; and (v) at T1 and T2, approximations were often offered rather than exact numbers. For all these reasons, the data cannot be seen as trustworthy. Instead, the remaining usable data represents an initial tentative signal.

Regarding proportion of ethnic minority staff, there was usable data for 31 organisations at T1 and 18 at T2. At both times, the average was taken among participants from the same organisation. Based on this, the proportion of CALD staff was stated to range from $8-100 \%(\mathrm{M}=43 \%)$ at T1 and from $8-100 \%(\mathrm{M}=44 \%)$ at T2. However, the trends at T1 (not reported here for brevity) show that the higher numbers were obtained among non-mainstream organisations that formally support ethnic minority clients (as expected), pushing the average up.

Regarding proportion of ethnic minority staff in management positions, one participant at T1 said N/A-Our organisation is a feminist collective flat structure (BL_1). There was usable data for 29 organisations at $\mathrm{T} 1$ and 18 at T2, and again the average was taken among participants from the same organisation at each time. Based on this, the proportion of CALD staff in management positions was stated to range from $0-100 \%(\mathrm{M}=13 \%)$ at $\mathrm{T} 1$ and from $0-20 \%(\mathrm{M}=6 \%)$ at $\mathrm{T} 2$, with the higher numbers at T1 among non-mainstream organisations (again, not reported here). At T2, almost all participants worked at organisations with ethnically diverse staff profiles $(96 \%)$ but very few were in management positions (6\%).

On either the anonymous satisfaction survey (SS) administered at the end of the program, the baseline (BL) survey administered prior to it, or the open-ended comments section on the online follow-up (FU) survey, some participants provided qualifying information regarding the representation of ethnic minority staff within their organisation. For example, some participants explained how CALD staff were represented in their organisation:

We are a small private practice with 2 GPs and 2 psychologists all from CALD backgrounds (FU_41).

We have CALD practitioners and staff from many varied ethnic communities. To name a few, these include South Sudanese, West African, Iran, Iraq, China, Malaysia, India, Afghanistan, Brazil, and Lithuania. We also have Aboriginal and Torres Strait Islander practitioners and program managers, as well as from other Australian states and territories (BL_102). 
Other participants indicated that CALD staff may not be represented in their team but are in the wider organisation. They said:

We have a number of different programs and CALD practitioners are spread based on their skills (BL_39).

No CALD background employees in small SV (sexual violence) team-(but) CALD workers (are) in broader DVAC team (BL_22).

Some participants indicated their organisations have intentions to grow their CALD staff representation. They said:

(I) have followed up with some of these teams for more information/clarification (re CALD representation), (and I) have distributed information (from your training) to colleagues, (but) the size of the organisation (being small) poses challenges for staff that reflect client diversity (FU_12).

I know that when I was employed (at organisation name), my manager was hoping to employ someone from (a) CALD background but didn't find anyone suitable. I also know we are trying to be more CALD inclusive-attending networking meetings in CALD services etc. (BL_109).

Finally, some participants noted there is recognition of low representation of CALD staff in management positions. They said:

It's very rare that (a) CALD group will achieve a manager position in this organisation (FU_4).

(Any other comments?) The importance of having CALD staff in management and power (SS_25).

The org as a whole I cannot totally speak for but I have not noticed a wide prevalence of CALD leadership positions (SS_88).

\subsubsection{Client Choice Regarding Ethnic Matching}

At T1, 19 participants did not answer the third part of this question; three said 'Not sure'; five said 'N/A-We have no CALD clients'; 30 said 'No'; and 55 said 'Yes'. At T2, 10 participants did not answer the question; two said 'N/A'; 12 said 'No'; and 20 said 'Yes'. Thus, not including the participants who selected N/A, 51\% of the total sample at T1 said their service organisation offers CALD clients choice about whether they would like an ethnically-matched service provider. This decreased to $48 \%$ at T2, which is somewhat suggestive of the ineffectiveness of the program on this element (see Table 5).

Table 5. Frequency data on client choice regarding ethnic matching.

\begin{tabular}{ccccc}
\hline & \multicolumn{3}{c}{ T1 } & \multicolumn{2}{c}{ T2 } \\
\cline { 2 - 5 } & $\mathbf{N}$ & $\mathbf{\%}$ & $\mathbf{N}$ & $\mathbf{\%}$ \\
\hline Total & 55 & 51 & 20 & 48 \\
Ethnic minority & 34 & 60 & 10 & 48 \\
Anglo & 21 & 42 & 10 & 48 \\
Mainstream & 34 & 46 & 12 & 44 \\
Non-mainstream & 19 & 63 & 7 & 47 \\
Specialised for sexual assault & 13 & 38 & 3 & 33 \\
Not specialised for sexual assault & 40 & 57 & 16 & 50 \\
\hline
\end{tabular}

Participants from the same organisation provided different responses to each other, so the unit of analysis became the service provider rather than their organisation. Descriptively, the data shows that at T1, more ethnic minority (T1 60\%, T2 48\%) than Anglo (T1 42\%, T2 48\%) service providers, more service providers in non-mainstream (T1 63\%, T2 47\%) than mainstream organisations (T1 46\%, T2 $44 \%$ ), and more service providers in organisations not specialised for sexual assault (T1 57\%, T2 50\%) 
than those that are (T1 38\%, T2 33\%) offer CALD clients choice about whether they would like an ethnically-matched service provider, but that these numbers mostly evened out at T2.

Some participants at $\mathrm{T} 1$ provided qualifying information around their response to this question, which helped to understand their choice better. For example, some noted that choice was offered as part of routine work (but did not necessarily state explicitly if this was related to ethnic matching):

Yes—always discuss preferences (BL_76).

Yes—we offer freedom of choice for counsellors (BL_46).

[Org name] is not a case management or crisis support service and has little face to face interaction with CALD clients. Client service roles are phone-based, and it is not always possible to identify $C A L D$ clients. [Org name] relies on bilingual staff to assist with translating when language barriers are present. Client services have a dedicated Aboriginal Contact Officer to assist with clients who identify as Aboriginal and/or Torres Strait Islander. CALD clients are given the opportunity to nominate a counsellor based on their language preferences (BL_53).

For some participants, choice around ethnic matching was offered within their organisation pending resource constraints. They said:

Yes-if available (BL_39).

Yes-where we can or refer for all matters (BL_59).

Sometimes—depending on availability and client preference (BL_29).

No-the offer of services is limited to CALD service availability (BL_75).

Finally, some participants noted that ethnic matching was not an intentional practice occurring within their organisation. They said:

No-not explicitly (BL_18).

N/A—from memory, no (BL_56).

No-we have no CALD staff (BL_109).

Yes_-Indig(enous) families but not necessarily other groups (BL_20).

\subsection{Training}

At T1, two participants did not answer the relevant question; 11 said 'N/A-I do not work at a service organisation'; 77 said 'No'; and 22 said 'Yes'. At T2, three participants did not answer the question; two said 'N/A'; 15 said 'No'; five said 'Yes' (but named this program); and 19 said 'Yes'. Thus, not including the participants who selected N/A or this program, $22 \%$ of the total sample at T1 said they had received training on culturally appropriate service provision for CALD victims/survivors of child sexual abuse while working at their service organisation. This had increased at T2 (51\%) but likely reflects the current program without it being explicitly named by participants. As such, it could not be claimed that the program effectively heightened general awareness of this issue in the field.

Some participants identified their source of training, and they included local mainstream or multicultural organisations as well as internal staff. One participant also said, Yes (a trainer within the organisation. It was a very short/general training though (BL_56). Another said: We have received training from [org name] on CALD clients experience of trauma, and separately we have received training from [org name] on sexual violence. Workers can opt to seek out specific training as part of their professional development, so some workers may have received more specialised training, e.g., our CNP program where workers speak to victims of sexual assault (FU_11). Overall, the results indicate that training in this area is nascent. 
Several participants offered qualitative feedback, including on the satisfaction survey, which asked questions like 'What did you like best about the program?' or 'Was there anything you thought was redundant in the program?' This feedback does not explicitly identify the need for training but does indirectly support the usefulness of further continued training in this area.

For example, some participants $(n=22)$ noted specific learnings from the program they particularly appreciated. These included learning about the barriers to disclosure and service uptake. As examples, some said:

The explanations for barriers to services in CALD communities was very helpful and interesting (SS_99).

(Liked best?) The barriers women/children from CALD communities experience in accessing support. Thank you very much (SS_70).

(Liked best?) Acknowledging the many different factors, specifically cultural and acculturative, that pose as barriers to disclosure (SS_92).

(Any other comments?) (I) have left today with a clearer understanding of barriers/challenges faced by CALD victims/survivors (SS_39).

I have learnt more about CALD and Western differences. I understand the importance of understanding CALD clients around CSA and the extreme barriers (SS_37).

Participants also appreciated learning about the new service delivery model proposed within the program. As some examples:

I love how you presented a model with principles underpinned by research and literature (SS_21).

(Liked best?) Ideas on providing "culturally competent" service provision and particularly your service delivery model -> I'm going to use (try!!) this in my work (SS_52).

Finally, some participants provided affirmation of the importance of organisational cultural competency, professional self-care, and sensitivity and honesty during client engagement. Some of these participants said:

Never thought of 'being (a) secondary victim'. (I) have to explore (this) more, thank you (SS_3).

(Liked best?) Ideas of cultural competency at (the) organisational level—good to easily apply to be more inclusive (SS_99).

(Any other comments?) Something that stuck out was to acknowledge difference in culture but don't make them feel different. Also not focusing on politeness to the point where victim's trauma is underplayed (SS_46).

Excellent! Although there was a lot of content I was familiar with, the challenges you raised by your questions has given me a lot to think about in how I provide service to CALD clients-how to make it easier for CALD clients to access service (SS_34).

In addition to specific learnings, some participants asked thought-provoking questions or made fruitful comments about tensions within their current practice and platforms regarding "where to from here'. For example, one asked, "(is there) more knowledge of diverse cultures where child abuse happens?" (SS_94) and another noted more generally that "the topic needs to be taken more in consideration" (SS_56).

Comments relating to the need for greater community awareness and the importance of champions were made. For example, some participants said:

Opportunity and role of community leaders (SS_45). 
When someone discloses, you might get one shot to put them on the right direction or help them. We, as a community, have to be knowledgeable, educated to support others (SS_3).

Potential leadership and drive to influence and change community attitudes within/for CALD communities - increase awareness of government and organisations and community responsibility (SS_47).

One key tension raised was around 'child-centred family-focused' work. For example, some said:

So important to consider CALD backgrounds but to keep your job focused on the client themselves is paramount (SS_80).

It was really interesting, I would have liked to go a bit deeper into possible ways to move forward with issues/barriers for victims for collectivist cultures, how to challenge the negative outcomes of communities punishing victims, whilst remaining cultural respectful (SS_68).

Another key tension was around mandatory reporting and the need to work at the client's pace given how little knowledge and confidence they have of social systems in Australia. As examples, participants said:

Many CALD women are unaware and/or have little confidence that they are equal in the eyes of the law - they have rights which are protected by law. Many believe Police and institutions operate in the same way as their home country. Many CALD women are financially abused and coerced. Work at the client's pace (SS_9).

Just a mindfulness that I think most people in the room (Qld session) were not mandatory reporters to Child Safety (social workers, counsellors, human service practitioners etc.) and there is a lot of fear among workers regarding reporting to Child Safety when developing trust (especially with CALD communities) and would be good to touch on navigating this (SS_65).

Finally, the long-standing systemic neglect of the needs and experiences of ethnic minority children and families in Australian child protection work was noted. One participant said:

In my mind, there is a long journey ahead for child protection agencies across the country to come up to speed in terms of cultural competency with CALD clients in most regards, unfortunately. Progress will be noted when cultural responsiveness is embedded as strongly for CALD families as it is for Aboriginal families and I say this with no disrespect to Aboriginal communities. We all know why Aboriginal practice approaches are so needed due to our past horrific practices (of the Stolen Generations). I would, however, like to see the word "culture" be associated with ALL cultures and an equal worth be placed on working effectively with CALD families (FU_23).

Overall, participants noted they would recommend this program to others, as its relevant reach was wide and cuts across personal and structural levels. As examples, they said:

My organisation provides services for all women no matter your background. I'll suggest that this program conduct this session across community levels (BL_52).

At times it was difficult to follow if you were speaking about the child victim or adult survivor of sexual abuse. Adults won't present to organisations (DHS [Department of Human Services] etc.) therefore I feel training individuals (as your training is presumably designed to do) is essential-the organisation is only as good as its frontline workers but many do not work as part of organisations (SS_16). 


\subsection{Multicultural Framework}

Table 6 contains descriptive data on service providers' ratings of their organisation's respect for ethnic diversity in principle and in practice. This is for the total sample, by the cultural background of the service provider (ethnic minority or Anglo), whether the service provider works at a mainstream or non-mainstream organisation, and whether the service provider works at an organisation specialised for sexual assault or not.

Table 6. Descriptive data on use of a multicultural framework.

\begin{tabular}{|c|c|c|c|c|c|c|c|c|c|c|}
\hline & \multicolumn{5}{|c|}{ T1 } & \multicolumn{5}{|c|}{ T2 } \\
\hline & $\mathbf{M}$ & SD & $\mathbf{N}$ & Min & Max & $\mathbf{M}$ & SD & $\mathbf{N}$ & Min & Max \\
\hline \multicolumn{11}{|c|}{ How respectful of ethnic diversity service organisation is in principle } \\
\hline Total & 4.1 & 0.9 & 111 & 2 & 5 & 4.4 & 0.7 & 42 & 3 & 5 \\
\hline Ethnic minority & 4.1 & 0.9 & 59 & 2 & 5 & 4.2 & 0.8 & 21 & 3 & 5 \\
\hline Anglo & 4.1 & 0.8 & 52 & 2 & 5 & 4.6 & 0.6 & 21 & 3 & 5 \\
\hline Mainstream & 4.0 & 0.9 & 74 & 2 & 5 & 4.3 & 0.8 & 28 & 3 & 5 \\
\hline Non-mainstream & 4.5 & 0.9 & 30 & 2 & 5 & 4.7 & 0.6 & 13 & 3 & 5 \\
\hline Specialised for sexual assault & 4.0 & 0.8 & 34 & 2 & 5 & 4.2 & 0.8 & 9 & 3 & 5 \\
\hline Not specialised for sexual assault & 4.2 & 0.9 & 70 & 2 & 5 & 4.5 & 0.7 & 32 & 3 & 5 \\
\hline \multicolumn{11}{|c|}{ How respectful of ethnic diversity service organisation is in practice } \\
\hline Total & 3.7 & 0.9 & 111 & 1 & 5 & 4.0 & 0.9 & 42 & 2 & 5 \\
\hline Ethnic minority & 3.8 & 1.0 & 59 & 1 & 5 & 4.0 & 1.0 & 21 & 2 & 5 \\
\hline Anglo & 3.7 & 0.8 & 52 & 2 & 5 & 3.9 & 0.8 & 21 & 2 & 5 \\
\hline Mainstream & 3.6 & 0.8 & 74 & 1 & 5 & 3.7 & 0.9 & 28 & 2 & 5 \\
\hline Non-mainstream & 4.2 & 0.8 & 30 & 2 & 5 & 4.7 & 0.7 & 13 & 3 & 5 \\
\hline Specialised for sexual assault & 3.8 & 0.7 & 34 & 2 & 5 & 4.0 & 0.8 & 9 & 3 & 5 \\
\hline Not specialised for sexual assault & 3.8 & 1.0 & 70 & 1 & 5 & 3.9 & 0.9 & 32 & 2 & 5 \\
\hline
\end{tabular}

The results show that for the total sample at both T1 and T2, ratings are higher for 'in principle' (T1 $\mathrm{M}=4.1, \mathrm{~T} 2 \mathrm{M}=4.4)$ than 'in practice' (T1 M=3.7, T2 M=4.0) but that both are still high. This suggests relatively good convergence between the rhetoric and implementation of a multicultural framework within service organisations. The results also show that ratings increased from T1 to T2, suggesting that the education program was effective in enhancing this component of cultural competency at the organisational level. However, as one participant importantly pointed out, Re (the two questions) - But we are always learning ( $\left.B L \_48\right)$.

The results also show that ratings are higher among service providers who work in non-mainstream organisations $(\mathrm{T} 1 \mathrm{M}=4.5, \mathrm{~T} 2 \mathrm{M}=4.7 ; \mathrm{T} 1 \mathrm{M}=4.2, \mathrm{~T} 2=4.7)$ than those who work in mainstream organisations ( $\mathrm{T} 1 \mathrm{M}=4.0, \mathrm{~T} 2 \mathrm{M}=4.3 ; \mathrm{T} 1 \mathrm{M}=3.6, \mathrm{~T} 2=3.7$ ), at both $\mathrm{T} 1$ and $\mathrm{T} 2$. This finding is consistent with expectations that organisations specialised for ethnic minority clients would be better in using a multicultural framework in both word and deed. However, the difference was considerable at T2 and suggests that mainstream organisations have sizeable room for improvement.

Finally, there were no or little differences at T1 between ethnic minority and Anglo service providers, nor between service providers who work at organisations specialised for sexual assault and those who do not. However, there was an observable increase among Anglo service providers (T1 M = 4.1, $\mathrm{T} 2 \mathrm{M}=4.6$ ) for 'in principle' ratings. This may suggest that support from their organisation to attend this program and obtain professional development training was particularly positively regarded.

One participant provided relevant qualitative data, appreciating that organisational responsibility was included in the program, not just the responsibility of frontline workers. Importantly, she highlights that the implementation of a multicultural framework is challenging and far from being realised:

I liked the part about cultural awareness of individuals and organisations. I've seen child-centric cultures in so many organisations, but it's really occurred to us it's just ticking a box for the government, it's really Western, not taking others into consideration (QEA Forum_Adel). 


\subsection{Data Collection}

At T1, one participant said 'Not sure' to the first part of the relevant question; seven said 'N/A-I do not work at a service organisation'; 20 said 'No'; and 84 (80\%; not including N/A) said 'Yes'. At T2, seven did not answer the question; two said 'No'; and 35 (80\%) said 'Yes'. Participants at T1 who wished to provide qualifying data also said:

Yes_but not very well! (BL_99).

Yes—only some programs collect CALD data (BL_94).

Within my program there is no data-until recently when I have requested to collect specific data for $C A L D$ and $a S W$ (social work) student to do research (BL_88).

At both $\mathrm{T} 1$ and T2, some participants from the same organisation provided different responses to each other to the second part of this question. To depict the best possible scenario, data was used from participants who said 'Yes' rather than 'No' and who ticked the highest number of variables. Of the 45 organisations for which there is data at T1, one said 'Not sure'; four said 'No'; and 40 (89\%) said 'Yes'. Of the 31 organisations for which there is data at T2, six said 'No' or did not respond; and 27 (87\%) said 'Yes'.

The change over time was small, indicating that the program was not effective in ensuring organisations collect ethnicity-related data. Prima facie, it appears that this aspect of organisational cultural competency is already being done well, which is why improvements are not being observed; however, selecting the most favourable data also somewhat inflates the proportion of organisations collecting this data. More precise, accurate research is required in the future.

As can be seen from Table 7 , the most common variables that organisations collect data on are languages spoken at home, the need for an interpreter, and country of birth. Those who provided a qualitative response under 'Other', and which was not synonymous with one of the listed variables on the survey, such as "ethnicity" or "preferred language", said the following: self-identified cultural identity, country of birth of parents, year of arrival if migrant, diet, and sexual identity/orientation. One also said, "We ask individual to advise us whether there are cultural issues we should be aware of (BL_102)" and another said, "Cultural background and means of connection (people, organisations, events) (BL_80)".

Table 7. Frequency data on organisations collecting data on ethnicity-related variables.

\begin{tabular}{ccccc}
\hline & \multicolumn{2}{c}{ T1 } & \multicolumn{2}{c}{ T2 } \\
\cline { 2 - 5 } & $\mathbf{N}$ & $\mathbf{\%}$ & $\mathbf{N}$ & $\mathbf{\%}$ \\
\hline Languages spoken at home & 37 & 93 & 27 & 100 \\
Need for interpreter & 35 & 88 & 26 & 96 \\
Country of birth & 36 & 90 & 26 & 96 \\
Citizenship & 22 & 55 & 15 & 56 \\
Ethnic background & 16 & 40 & 9 & 33 \\
Other & 15 & 38 & 5 & 19 \\
\hline
\end{tabular}

\subsection{Promotional Inclusiveness}

Within the month prior to the programs being delivered (i.e., between 25 February and 25 March 2019), the homepage and each main tab on the websites of the 61 organisations that registered were explored for their visual inclusiveness (Yes or No). For the purposes of this study, images of only Indigenous Australians did not constitute as ethnically diverse/visually inclusive. However, not all registrants attended the programs on the day, or completed or named their organisation on the baseline survey, so only data for the 46 organisations named on the baseline survey were analysed here. Visual inclusiveness was explored again six months later (25 September 2019).

At baseline, three organisations were universities rather than service organisations, and so were not included in further analyses. Of the remaining 43 organisations, three (7\%) had no website, one 
( $2 \%$ ) did not use any images, and four (9\%) used inanimate images not of people (e.g., flowers); likely to be intentional as part of branding and/or informed by costs. Excluding these, 24 were mainstream organisations and 13 (54\%) had websites deemed visually inclusive. Three of the mainstream organisations that did not have images of people from ethnic minority communities did, however, provide different language options, thereby addressing linguistic accessibility. All 11 multicultural ('non-mainstream') organisations were visually inclusive.

At follow-up, 16 of the 24 (67\%) mainstream organisations were deemed visually inclusive. Of the three additional organisations, one was national and two were state-based. The only small increase in the proportion of mainstream organisations implementing this aspect of cultural competency may not necessarily indicate the program's ineffectiveness about this but rather that organisations may not have sufficient funds or other resources to prioritise and implement it.

\subsection{Links with Local Ethnic Minority Organisations}

There appeared to be a small amount of confusion with the question regarding links with other local CALD community organisations or members within such organisations. Most answered it based on what they currently do (as the question intended to ascertain), but a small number of participants seemed to base it on what they would do (indicative of a future intention should an ethnic minority victim/survivor present to their service). Thus, the validity of this data appears slightly compromised, and in turn should be treated with some caution.

Table 8 contains the descriptive data for the total sample, by the cultural background of the service provider, and by types of service organisations. As expected, it shows that non-mainstream organisations have stronger links ( $\mathrm{T} 1 \mathrm{M}=3.1, \mathrm{~T} 2 \mathrm{M}=3.7)$ than mainstream organisations $(\mathrm{T} 1 \mathrm{M}=2.1$, $\mathrm{T} 2 \mathrm{M}=2.1$ ) at both $\mathrm{T} 1$ and $\mathrm{T} 2$. However, it also shows that organisations not specialised for sexual assault have stronger links ( $\mathrm{T} 1 \mathrm{M}=2.6, \mathrm{~T} 2 \mathrm{M}=2.7)$ than organisations specialised for sexual assault ( $\mathrm{T} 1 \mathrm{M}=2.1, \mathrm{~T} 2 \mathrm{M}=2.6$ ) at $\mathrm{T} 1$. This seems to suggest that the intensity of clinical work involved with sexual assault victims/survivors, in a resource-poor climate, limits the ability of organisations specialised for sexual assault to take an intersectional approach for its ethnic minority clients. After the program, however, the difference closed, suggesting that the program may have had an impact on promoting intersectionality.

Table 8. Descriptive data on links with local CALD community organisations.

\begin{tabular}{cccccccccccc}
\hline & \multicolumn{4}{c}{ T1 } & \multicolumn{6}{c}{ T2 } \\
\cline { 2 - 12 } & M & SD & N & Min & Max & M & SD & N & Min & Max \\
\hline Total & 2.4 & 0.9 & 107 & 1 & 4 & 2.7 & 1.0 & 43 & 1 & 4 \\
Ethnic minority & 2.5 & 1.0 & 56 & 1 & 4 & 3.0 & 0.8 & 23 & 1 & 4 \\
Anglo & 2.3 & 0.8 & 51 & 1 & 4 & 2.7 & 1.1 & 21 & 1 & 4 \\
Mainstream & 2.1 & 0.8 & 73 & 1 & 4 & 2.1 & 0.7 & 27 & 1 & 3 \\
Non-mainstream & 3.1 & 0.9 & 28 & 1 & 4 & 3.7 & 0.5 & 15 & 3 & 4 \\
Specialised for sexual assault & 2.1 & 0.8 & 34 & 1 & 4 & 2.6 & 0.9 & 9 & 1 & 4 \\
Not specialised for sexual assault & 2.6 & 0.9 & 67 & 1 & 4 & 2.7 & 1.0 & 32 & 1 & 4 \\
\hline
\end{tabular}

Overall, there was an increase in ratings of links with CALD organisations from T1 to T2 for the total sample (T1 M = 2.4, T2 $\mathrm{M}=2.7)$, and among ethnic minority $(\mathrm{T} 1 \mathrm{M}=2.5, \mathrm{~T} 2 \mathrm{M}=3.0)$ and Anglo ( $\mathrm{T} 1 \mathrm{M}=2.3, \mathrm{~T} 2 \mathrm{M}=2.7$ ) service providers. Two participants also provided qualitative data regarding links with local community organisations. They said:

Re (this question): My team yes, broadly no (SS_44).

(Re this question) to my knowledge leaves all responsibility for connections to the Multicultural Services team within DCP (Department of Child Protection) - which is possibly 4-5 staff members who assist/provide advice across 19 offices and program areas (BL_85). 


\section{Discussion}

\subsection{Summary of Key Findings}

The onus for cultural competency does not all belong to frontline service providers; structural support from their service organisation/institution is equally required (Sawrikar 2017). The following forms of organisational/institutional support were seen as mandatory in this study: (i) using interpreters trained in matters to do with sexual assault, and service organisations providing such training to interpreters; (ii) having an ethnically diverse workforce, including in management positions; (iii) providing regular 'cultural competency' training; (iv) using 'a multicultural framework'; and (v) collecting data on all ethnicity-related variables. Practices with interpreters are a substantive work issue, and so have been addressed separately in another paper; only the remaining elements are reported on here. Two forms of organisational/institutional support were seen as ideal and also explored in this study: (i) using visual images of an ethnically diverse target client group in promotional materials; and (ii) having strong links with local CALD/ethnic minority community members and organisations.

Positively, most service organisations employed ethnic minority staff. However, they were more often employed in CALD-specialised rather than in mainstream organisations. Moreover, approximately $16 \%$ of service organisations do not have any ethnic minority staff, which is problematic and in need of address because it indicates that a sizeable number of service organisations are wholly white. They therefore do not have the diversity of knowledge that both colleagues and clients require and benefit from while working in a multicultural society. It is not known with confidence how many ethnic minority employees are in management positions, but it appears very low (approximately 6-13\%), even among those who work in CALD-specialised organisations. This trend reflects systemic racial bias (white privilege) — the systemic racial favouring of opportunities, especially those with power, to white Australians - else they would be proportionate to the representation of ethnic minority people in Australia's population at approximately 33\% (Australian Bureau of Statistics (ABS)). Overall, there is some recognition by service organisations of the need to address the low representation of 'CALD' staff, including in management positions, in turn indicative of awareness of institutionally racist barriers.

Although it occurs inconsistently (at approximately half the time), ethnic minority staff, and staff working in CALD-specialised organisations, are more likely to offer ethnic minority clients choice about whether they would like an ethnically-matched service provider. Overall, the program was ineffective in changing the number of service providers that offer this choice. As it is not known why, future in-depth qualitative research is required to help unpack the barriers to routinely offering ethnic matching, especially among Anglo staff and in mainstream organisations. Interestingly, service providers working in organisations not specialised for sexual assault more often offer ethnic matching, suggesting that organisations specialised for sexual assault do not or are unable to take an intersectional lens; de-prioritising meeting cultural needs to the needs of victims/survivors of sexual assault. Again, further research would be required to explore this phenomenon more deeply.

The proportion of service providers who reported having received training on culturally appropriate service provision for CALD victims/survivors of child sexual abuse while working at their current service organisation had increased over time. However, this does not necessarily indicate that the program was effective in heightening a general awareness of this issue in the field as their response may be about the current program. When training other than this program had been received, it was by local mainstream or multicultural organisations as well as internal staff but seen as short or general. Overall, a desire for in-depth knowledge, appreciation of the program's content, and ideas for future work were all expressed; indirectly supporting the usefulness of regular training. In particular, learning about the steepness of the barriers to disclosure and service uptake and cultural differences that contribute to this were appreciated, as were framing service delivery models and elements to help guide future practice. Child-centred culturally respectful practice, mandatory reporting, and the general neglect of this population within Australian social service policy and practice 
were key current tensions. Potential for community leaders and champions to increase awareness of CSA and relevant services among ethnic minority communities represent key areas for future participatory research and advocacy.

The use of a multicultural framework-operationalised in this study as respect for ethnic diversity - was rated as higher 'in principle' than 'in practice', and higher among CALD-specialised organisations, as expected. Ratings also increased over time, suggestive of the program's effectiveness. Support from organisations to attend professional development opportunities, such as this education program, are highly regarded by staff and perceived as their organisation implementing a multicultural framework. Overall, the implementation of a multicultural framework is challenging and represents ongoing learning.

The proportion of service organisations collecting data on ethnicity-related variables did not increase over time, indicating that the program was not effective in improving this aspect of cultural competency. However, this may be because it is already being done well. Overall, more precise and accurate information is required about the extent to which organisations collected relevant data. The most common variables on which data is collected include languages spoken at home, the need for an interpreter, and country of birth. Less frequently, organisations also collect data on citizenship, religion, ethnicity, year of arrival, social connectedness, and diet.

All CALD-specialised organisations had visually inclusive websites; just over half of the mainstream organisations had visually inclusive websites; and a small number of mainstream organisations were not visually inclusive, but their website offered different language options. These proportions did not change substantially over time, indicating that the program was not really effective in addressing it. However, resource constraints may have an impact on being able to prioritise or implement it, which future research could help confirm with a more nuanced understanding around an organisation's choices for promotional branding and images.

As expected, CALD-specialised organisations have stronger links with local CALD community organisations. However, unexpectedly, organisations not specialised for sexual assault have stronger links than those specialised for sexual assault. This again suggests that the intensity of clinical work involved with sexual assault victims/survivors, in a resource-poor climate, limits the ability of such organisations to take an intersectional approach for its CALD clients. Still, ratings of links did improve over time, suggesting that the program was effective in promoting intersectionality and this element of organisational cultural competency.

In summary, these results are a first: there are no prior in-depth programs designed for service providers and organisations across western multicultural international contexts about how to work well with ethnic minority victims/survivors of CSA. Such knowledge is typically acquired by practitioners ad hoc after engaging with clients who have broken through the steep barriers to disclosure and help-seeking. It is therefore not possible to compare these results to other studies, but they do invite the opportunity to build from the benchmarks they provide. Future studies examining social service provision for people from ethnic minority communities (not just for CSA but for DFV or mental ill-health generally for example) can compare their results to those obtained here regarding the ethnic diversity of their workforce and management teams, how often they provide PD training opportunities and how these are experienced by staff, ratings of the use of 'a multicultural framework', how often ethnicity-related data is collected, how visually inclusive the organisation is, and how strong their links with local ethnic minority community members and organisations are.

\subsection{Methodological Strengths and Limitations and Areas for Future Research}

The main aim of Stage 1 was to develop a program that educates mental health service providers about ethnic minority victims/survivors of CSA and their needs in the clinical setting, and then examine whether and how it improved their and their organisation's cultural competency in the moderate term. It thus used a mixed-methods and longitudinal design; triangulating quantitative survey data with qualitative open-ended data over a six-month period. Its contents were also informed by a 
systematic literature review in the area, thereby building empirical data collection on exhaustive theoretical foundations.

Despite its rigorous design, and contribution of new and innovative data, some methodological limitations need to be noted. The first is the sample size, which was about half of what was anticipated. Although the sample was nationally representative, interest in the area was overestimated, especially among medical professionals (GPs and psychiatrists). A power analysis was conducted to examine whether the sample size could be deemed or was close to being sufficient (Cohen 1992). The cross-sectional statistical tests in this study were of differences between two independent means. Thus, to detect a medium effect size (ES) at alpha $(\alpha)$ set to 0.05 , a sample of 64 per group was required. This was nearly obtained when examining the data set by the cultural background of the service provider (59 ethnic minority and 53 Anglo) but only at baseline.

Overall, future replication studies with larger samples and all target audiences represented would be required to verify the tentative findings reported here. Such studies could also link the data sets with a unique identifier to conduct repeated measures analyses, and therefore test for statistically significant changes over time to empirically establish the effectiveness of the program. Positively, however, the mean score on the T1 satisfaction survey—rated on a Likert scale from $1=$ Overall, not at all satisfied with the program to $5=$ Overall, completely satisfied with the program —was $4.2(\mathrm{SD}=0.7$, $\mathrm{n}=99$ ). This provides strong supporting evidence for the overall effectiveness of the program, which was high given the complexity and sensitivity of the topic.

A larger sample with arguably less onus to repeatedly provide utmost assurance of anonymity of survey material, and which would then allow for longitudinal statistical analyses to be conducted, would then require consideration of the number of hypotheses on potential for type I and type II errors. This study tested nine hypotheses, and such a large number would need to adjust for this by reducing the normal set alpha from 0.05 to 0.01 or even less. This is not relevant here as the study's relatively small sample size and non-matched data sets over time meant that only descriptive statistics were reported, but it is important to acknowledge this for future replication studies with larger samples.

Finally, one participant at T1 said "Some of the questions in the questionnaire used very complex English making them very difficult to understand" (SS_4). It is not known if this position represents those of others too, but it does need to be acknowledged as potentially influencing the validity of responses for some participants. Overall, the questionnaire design was informed by the need for clarity/unambiguity in meaning and so provided full and sufficient descriptions within each question, balanced against the need to keep the total number of questions to a minimum to help reduce participant fatigue. Given how few attendees made negative comments, the evaluation instrument is regarded as valid. Indeed, another participant said, "This survey has been really useful in identifying gaps around CALD clients" (SS_60).

\subsection{Implications for Future Research and Practice}

It was beyond the word scope to delve into deep analysis of the verbatim quotes. They were, however, documented as fully as possible to honour their contributions, and act as a springboard for a future research agenda. Ample directions to improve the cultural competency of social service organisations available to ethnic minority victims/survivors of CSA are possible, and can be rigorously evaluated for their impact on relevant process and outcome variables (e.g., ratings of a multicultural framework in principle and in practice, client satisfaction, etc.).

These various directions may include: (i) intentionally increasing the recruitment of ethnic minority staff, including in management positions, to quotas that reflect the local milieu; (ii) mandating practice that ensures ethnic minority clients are offered choice about ethnically matched service providers; (iii) ensuring all staff receive in-depth training in the area (such as completing the accessible online version of this program); (iv) making data collection of ethnicity-related variables mandatory; (v) rebranding websites and other promotional materials to be visually inclusive; and (vi) reaching out to establish and nurture links with local ethnic minority community organisations from which tacit intel can 
be borrowed. Investing in such research helps develop evidence-based policies and sophisticated knowledge around what best supports good practice with a highly marginalised client group.

\section{Conclusions}

What constitutes as good service provision for ethnic minority victims/survivors of CSA is complex, and as such can be overwhelming. Due to the low uptake of services, practitioners may not have access to on-the-job learning opportunities, and due to low research may not have confidence in any acquired practice wisdom. Studies that help clearly map what the components of good practice might look like help promote the efficiency and effectiveness of organisations. In turn, this promotes positive flow-on effects for clients who benefit greatly from a treatment system that is informed and ready to receive and support them through the complex narrative of their trauma. To this end, a new service delivery model was developed and delivered to the participants, and was received well. It was grounded in an exhaustive systematic literature review, and framed within intersectionality to ensure the psychosocial experience of ethnic minority victims/survivors of CSA was less at risk of universalist assumptions. The need for ongoing critical engagement with relevant literature as it updates remains.

Author Contributions: The author is responsible for all stages of the research: conceptualisation, methodology, data collection, curation and analysis, writing, project administration, and funding acquisition. The author has read and agreed to the published version of the manuscript.

Funding: This research was partly funded by an internal Research Encouragement Grant scheme administered by the Faculty of Health at Griffith University.

Conflicts of Interest: The author declares no conflict of interest. The funders had no role in the design of the study; in the collection, analyses, or interpretation of data; in the writing of the manuscript, or in the decision to publish the results. The manuscript has not been published, nor is under consideration, elsewhere. Content in the Introduction ('Background'), Method, and Discussion ('Methodological strengths and limitations') overlaps with other journal articles prepared from this project, and content from the Results and Discussion overlaps with the full Technical Report prepared from this project. However, each journal article differs from these research outputs because the Technical Report contains full detail about the study's methodology and process evaluation providing a more comprehensive audit trail for readers to be able to refer to, and the shorter journal articles allow readers to focus on singular specific issues.

\section{References}

Australian Bureau of Statistics (ABS). 2016. Census of Population and Housing: Reflecting Australia-Stories from the Census. Catalogue No. 2071.0. Canberra: ABS.

Ahmed, Shama. 2004. Preventative Services for Black and Minority Ethnic Group Children and Families: A Review of Recent Literature. A paper for The National Evaluation of the Children's Fund. Birmingham: University of Birmingham.

Alaggia, Ramona. 2001. Cultural and religious influences in maternal response to intrafamilial child sexual abuse: Charting new territory for research and treatment. Journal of Child Sexual Abuse 10: 41-60. [CrossRef] [PubMed]

Allimant, Annabelle, and Beata Ostapiej-Piatkowski. 2011. Supporting Women from CALD Backgrounds Who Are Victims/Survivors of Sexual Violence: Challenges and Opportunities for Practitioners. Melbourne: Australian Institute of Family Studies.

Babacan, Hurriet. 2006. Literature Review: Service/Response Models in Child Protection for Culturally Diverse Communities. Report prepared for the Department of Child Safety, Brisbane, Queensland, Australia.

Barn, Ravinder, Ruth Sinclair, and Dionne Ferdinand. 1997. Acting on Principle: An Examination of Race and Ethnicity in Social Services Provision for Children and Families. London: British Agencies for Adoption and Fostering.

Bernard, Claudia. 2002. Parental maltreatment of black children in the context of societal racism. Child and Family Social Work 7: 239-51. [CrossRef]

Boakye, Kofi E. 2009. Culture and nondisclosure of child sexual abuse in Ghana: A theoretical and empirical exploration. Law and Social Inquiry 34: 951-79. [CrossRef]

Bond, Michael H. 2002. Reclaiming the individual from Hofstede's ecological analysis-A 20-year odyssey: Comment on Oyserman et al. (2002). Psychological Bulletin 128: 73-77. [CrossRef] 
Boushel, Margaret. 2000. What kind of people are we? 'Race', anti-racism and social welfare research. British Journal of Social Work 30: 71-89. [CrossRef]

Chan, Yuk-chung, Gladys L. T. Lam, and Wan-Chaw Shae. 2011. Children's views on child abuse and neglect: Findings from an exploratory study with Chinese children in Hong Kong. Child Abuse and Neglect 35: 162-72. [CrossRef]

Chand, Ashok. 2005. Do you speak English? Language barriers in child protection social work with minority ethnic families. British Journal of Social Work 35: 807-21. [CrossRef]

Chand, Ashok, and June Thoburn. 2005. Research review: Child and family support services with minority ethnic families-what can we learn from research? Child E Family Social Work 10: 169-78.

Chuan, Christeena, and Christine Flynn. 2006. Children and Young People of Culturally and Linguistically Diverse (CALD) Backgrounds in out of Home Care in NSW: Support Strategies, Challenges, and Issues: A Qualitative Research. Report prepared for Association of Children's Welfare Agencies (ACWA). Sydney: ACWA.

Cohen, Jacob. 1992. A power primer. Psychological Bulletin 112: 155-59. [CrossRef]

Denzin, Norman K., and Yvonna S. Lincoln. 2018. The Sage Handbook of Qualitative Research, 5th ed. Beverly Hills: Sage.

Di Angelo, Robin. 2018. White Fragility: Why It's so Hard for White People to Talk about Racism. Boston: Beacon Press.

Fattah, Kazi N., and Zarina N. Kabir. 2013. No place is safe: Sexual abuse of children in rural Bangladesh. Journal of Child Sexual Abuse 22: 901-14. [CrossRef]

Fontes, Lisa A. 2005. Child Abuse and Culture: Working with Diverse Families. New York: Guilford Press.

Fontes, Lisa A., and Carol Plummer. 2010. Cultural issues in disclosures of child sexual abuse. Journal of Child Sexual Abuse 19: 491-518. [CrossRef] [PubMed]

Futa, Kristine T., Eugenia Hsu, and David J. Hansen. 2001. Child sexual abuse in Asian American families: An examination of cultural factors that influence prevalence, identification, and treatment. Clinical Psychology: Science and Practice 8: 189-209. [CrossRef]

George, Sheba, Nelida Duran, and Keith Norris. 2014. A systematic review of barriers and facilitators to minority research participation among African Americans, Latinos, Asian Americans, and Pacific Islanders. American Journal of Public Health 10: e16-e31. [CrossRef] [PubMed]

Giglio, Michelle. 1997. Child protection and cultural difference: issues for NESB-Non-English speaking background-Communities. Child Abuse Prevention 5: 4-7.

Gilligan, Philip, and Shamim Akhtar. 2005. Child sexual abuse among Asian communities: Developing materials to raise awareness in Bradford. Practice (UK) 17: 267-84. [CrossRef]

Gough, David, and Margaret A. Lynch. 2002. Culture and child protection. Child Abuse Review 11: 341-44. [CrossRef]

Haboush, Karen L., and Hala Alyan. 2013. “Who can you tell?" Features of Arab culture that influence conceptualization and treatment of childhood sexual abuse. Journal of Child Sexual Abuse 22: 499-518. [CrossRef]

Hackett, W. L., and Katharine Cahn. 2004. Racial Disproportionality in the Child Welfare System in King County, Washington. Report prepared for King County Coalition on Racial Disproportionality. Washington, DC: King County Coalition on Racial Disproportionality.

Hall, Jonathon, and Sonia Valdiviezo. 2020. The social worker as language worker in a multilingual world: Educating for language competence. Journal of Social Work Education 56: 17-29. [CrossRef]

Harran, Evender. 2002. Barriers to effective child protection in a multicultural society. Child Abuse Review 11: 411-14. [CrossRef]

Hofstede, Geert H. 1980. Culture's Consequences: International Differences in Work-Related Values. Beverly Hills: Sage Publications.

Jewkes, Rachel, Loveday Penn-Kekana, and Hetty Rose-Junius. 2005. "If they rape me, I can't blame them": Reflections on gender in the social context of child rape in South Africa and Namibia. Social Science and Medicine 61: 1809-20. [CrossRef]

Kanukollu, Shanta N., and Ramaswami Mahalingam. 2011. The idealized cultural identities model on help-seeking and child sexual abuse: A conceptual model for contextualizing perceptions and experiences of South Asian Americans. Journal of Child Sexual Abuse 20: 218-43. [CrossRef] [PubMed]

Karthiga, R. K. Jaishree, Arulappan Tamilselvi, and Roopa Ravikumar. 2014. Child sexual abuse in Madurai, India: A literary review and empirical study. Journal of Child Sexual Abuse 23: 727-44. [CrossRef] [PubMed] 
Korbin, Jill. 2008. Child Neglect and Abuse across Cultures. In Contexts of Child Development Culture, Policy and Intervention. Edited by G. Robinson, U. Eickelkamp, J. Goodnow and I. Katz. Darwin: Charles Darwin University Press, pp. 122-30.

Lesmana, Corkorda B. J., Luh Ketut Suryani, and Niko Tiliopoulos. 2015. Cultural considerations in the treatment of mental illness among sexually abused children and adolescents: The case of Bali, Indonesia. New Directions for Child and Adolescent Development 2015: 109-16. [CrossRef]

Ma, Ellen Y. M., and Frendi W. S. Li. 2014. Developmental trauma and its correlates: A study of Chinese children with repeated familial physical and sexual abuse in Hong Kong. Journal of Traumatic Stress 27: 454-60. [CrossRef]

Maiter, Sarah, Ramona Alaggia, Adrienne S. Chan, and Bruce Leslie. 2017. Trial and error: attending to language barriers in child welfare service provision from the perspective of frontline workers. Child and Family Social Work 22: 165-74. [CrossRef]

Maitra, Begum. 2005. Culture and child protection. Current Paediatrics 15: 253-59. [CrossRef]

Meng, Liu. 2002. Rebellion and revenge: The meaning of suicide of women in rural China. International Journal of Social Welfare 11: 300-9. [CrossRef]

O'Hagan, Kieran. 1999. Culture, cultural identity, and cultural sensitivity in child and family social work. Child and Family Social Work 4: 269-81. [CrossRef]

Osterling, Kathy L., Amy DAndrade', and Michael J. Austin. 2005. Understanding and Addressing Disproportionality in the front end of the Child Welfare System. Bay Area: Centre of Social Services Research.

Plummer, Carol A., and Wambui Njuguna. 2009. Cultural protective and risk factors: Professional perspectives about child sexual abuse in Kenya. Child Abuse and Neglect 33: 524-32. [CrossRef]

Reavey, Paula, Bipasha Ahmed, and Anamika Majumdar. 2006. 'How can we help when she won't tell us what's wrong?' Professionals working with South Asian women who have experienced sexual abuse. Journal of Community and Applied Social Psychology 16: 171-88. [CrossRef]

Sale, Annabel U. 2006. Paralysed around culture. Community Care 1614: 28-29.

Sawrikar, Pooja. 2015. How effective do families of non-English speaking background (NESB) and child protection caseworkers in Australia see the use of interpreters? A qualitative study to help inform good practice principles. Child and Family Social Work 20: 396-406. [CrossRef]

Sawrikar, Pooja. 2017. Working with Ethnic Minorities and across Cultures in Western Child Protection Systems. London: Routledge.

Sawrikar, Pooja. 2018a. My Double Whammy: Being a Brown Woman in Western Academia. Available online: https://medium.com/@p.sawrikar/my-double-whammy-being-a-brown-woman-in-western-academiaa36bf73e2b09?source=friends_link\&sk=3489539882af83b501fc07476b142a47 (accessed on 3 April 2020).

Sawrikar, Pooja. 2018b. A Critical Reflection on Being an Ethnic Minority Researcher of Child Sexual Abuse in Ethnic Minority Communities: Implications for Social Work and Sociology. Available online: https://medium.com/@p.sawrikar/chasing-a-dream-is-racial-equality-attainable-8bcc7329402e? source=friends_link\&sk=703941d8308bbfb4ac0b418832ef98fa (accessed on 3 April 2020).

Sawrikar, Pooja. 2019a. Musings on the Maths of Unpaid Labour and Dissent from the Peer Review Process. Available online: https://medium.com/@p.sawrikar/dear-women-of-colour-scholars-advocate-for-yourself804bd65e16a9?source=friends_link\&sk=9f9cd6f99f423d4f3ede714c8fc03507 (accessed on 3 April 2020).

Sawrikar, Pooja. 2019b. The Development and Evaluation of an Education Program for Service Providers about Culturally and Linguistically Diverse CALD Client Victims/Survivors of Child Sexual Abuse: Technical Report 1 Full Report. Brisbane: Griffith University. [CrossRef]

Sawrikar, Pooja, and Ilan Katz. 2008. Enhancing Family and Relationship Service Accessibility and Delivery to Culturally and Linguistically Diverse (CALD) Families in Australia. Refereed Issues paper prepared for the Australian Family Relationships Clearinghouse (AFRC), Australian Institute of Family Studies (AIFS), Issues No. 3. Melbourne: Australian Institute of Family Studies.

Sawrikar, Pooja, and Ilan Katz. 2009. How useful is the term "Culturally and Linguistically Diverse (CALD)" in the Australian social policy discourse? In Refereed Conference Paper, Australian Social Policy Conference (ASPC). Sydney: University of New South Wales.

Sawrikar, Pooja, and Ilan Katz. 2017a. Barriers to disclosing child sexual abuse (CSA) in ethnic minority communities: A review of the literature and implications for practice in Australia. Children and Youth Services Review 83: 302-15. [CrossRef] 
Sawrikar, Pooja, and Ilan Katz. 2017b. How aware of child sexual abuse (CSA) are ethnic minority communities? A literature review and suggestions for raising awareness in Australia. Children and Youth Services Review 81: 246-60. [CrossRef]

Sawrikar, Pooja, and Ilan Katz. 2017c. The treatment needs of victims/survivors of child sexual abuse (CSA) from ethnic minority communities: A literature review and suggestions for practice. Children and Youth Services Review 79: 166-79. [CrossRef]

Sawrikar, Pooja, and Ilan Katz. 2018a. Proposing a model of service delivery for victims/survivors of child sexual abuse (CSA) from ethnic minority communities in Australia. Journal of Social Service Research 44: 730-48. [CrossRef]

Sawrikar, Pooja, and Ilan Katz. 2018b. Preventing child sexual abuse (CSA) in ethnic minority communities: A literature review and suggestions for practice in Australia. Children and Youth Services Review 85: 174-86. [CrossRef]

Sawrikar, Pooja, and Donna McAuliffe. 2019. Introduction to Special Issue on Personal Essays in Social Science (Editorial). Social Sciences 8: 325. [CrossRef]

Shalhoub-Kevorkian, Nadera. 2000. Blocking her exclusion: A contextually sensitive model of intervention for handling female abuse. Social Service Review 74: 620-34. [CrossRef]

Stewart, Sarah. 2005. Suicidality, interpersonal trauma and cultural diversity: A review of the literature. Australian e-Journal for the Advancement of Mental Health (AeJAMH) 4: 21. [CrossRef]

Sulimani-Aidan, Yafit, and Rami Benbenishty. 2013. Child maltreatment reports in Israel: The intersection between community socioeconomic characteristics and ethnicity. American Journal of Orthopsychiatry 83: 29-36. [CrossRef] [PubMed]

Thanki, Vyomesh. 2007. Ethnic diversity and child protection. Children and Society 8: 232-44. [CrossRef]

Tishelman, Amy C., and Robert Geffner. 2010. Forensic, cultural, and systems issues in child sexual abuse cases-Part 1: An introduction. Journal of Child Sexual Abuse 19: 485-90. [CrossRef]

Triandis, Harry C. 1990. Theoretical concepts that are applicable to the analysis of ethnocentricism. In Applied Cross-Cultural Psychology. Edited by Richard W. Brislin. New York: Sage.

Ullman, Sarah E., and Henrietta H. Filipas. 2005. Ethnicity and child sexual abuse experiences of female college students. Journal of Child Sexual Abuse 14: 67-89. [CrossRef] [PubMed]

Walker, Steven. 2002. Culturally competent protection of children's mental health. Child Abuse Review 11: $380-93$. [CrossRef]

Weeks, Wendy. 2002. Access and equity in services against sexual violence. Women against Violence: An Australian Feminist Journal 11: 22-34.

Welbourne, Penelope. 2002. Culture, children's rights and child protection. Child Abuse Review 11: $345-58$. [CrossRef]

Westby, Carol E. 2007. Child maltreatment: A global issue. Language, Speech E Hearing Services in Schools 38: 140-48.

Westlake, David, and Rebecca K. Jones. 2018. Breaking down language barriers: A practice-near study of social work using interpreters. The British Journal of Social Work 48: 1388-408. [CrossRef]

Wilson, Melba. 1994. Crossing the Boundary: Black Women Survive Incest. Seattle: Seal Press.

Yick, Alice G. 2007. Role of culture and context: Ethical issues in research with Asian Americans and immigrants in intimate violence. Journal of Family Violence 22: 277-85. [CrossRef]

(C) 2020 by the author. Licensee MDPI, Basel, Switzerland. This article is an open access article distributed under the terms and conditions of the Creative Commons Attribution (CC BY) license (http://creativecommons.org/licenses/by/4.0/). 